\title{
THE IMPACT OF CHRONIC DISEASE AND DISABILITY ON THE ELDERLY
}

\begin{abstract}
Health care systems for elderly people should aim to delay the onset of illness, reducing the final period of infirmity and illness to the shortest possible time. The most effective way to achieve this is by health education and preventative medicine to maintain EALES CJ, PhD

Department of Physiotherapy, University of the Witwatersrand, Johannesburg

mobility and function. Changes in life style even in late life may result in improved health, effectively decreasing the incidence of chronic diseases associated with advancing age. This paper presents the problems experienced by elderly persons with chronic diseases and disabilities with indications for meaningful therapeutic interventions.
\end{abstract}

\section{KEYWORDS: ELDERLY, CHRONIC DISEASE, HEALTH EDUCATION, PREVENTION, MANAGEMENT}

\section{INTRODUCTION}

It has been suggested that successful aging is a prolongation of minimal illness and disability coupled with a maximum participation in, and enjoyment of life (Baltes and Baltes, 1991). If we accept this definition of aging we would agree with Gonzalez-Aragon (1989) when he suggests that psychological factors are more decisive than chronological age to predict quality of life during old age. Different cultural groups attach different meanings to the word "old" and we have to consider the norms and definitions for our own country in order to find the most meaningful definition. Perhaps it is true to say that although we know that we grow older we don't really know when we become old. We become old when we declare ourselves "old". For this reason it is so important to stop speaking prematurely of others and ourselves as “old" (Willing, 1981).

Two common life events cause stress in the elderly, the death of a spouse, and the loss of physical health. A painful or limiting chronic condition can also reduce feelings of self-worth and competence. The loss of health reduces the elderly person's capacity to participate in daily activities, this threatens the sense of control over environmental challenges leading to feelings of helplessness and despair. However, we should not forget that man is mortal and that natural death can occur with or without disease (Fries, 1980). There is an emerging emphasis on wellness and that the elderly should become more involved and responsible for themselves (Carlsen, 1996).

Within an elderly population the different age groups grow at different rates. The fastest growing age segment in many countries is the "old" usually defined as persons over the age of 80 years. A broad classification of the elderly is that persons between the ages of 65 and 74 years are considered as the "young old", and that those between the ages of 75 and 85 are "middle old" and one is only considered "old" is after the age of 85 years.

We should however, bear in mind that individuals age at different rates and that there are remarkable variations between individuals.

It is generally believed that the aim of the health care system for elderly people should be to delay the onset of illness, reducing the final period of infirmity and illness to the shortest possible time. The most effective way to achieve this is by health education and preventative medicine to maintain mobility and function. Changes in life style even in late life may result in improved health, effectively decreasing the incidence of chronic diseases associated with advancing age (Rabbit 1992).

\section{POPULATION AGING IN THE DEVELOPED AND DEVELOPING WORLDS}

Internationally, the population over the age of 65 is growing at a rate of 2.5 per cent per year. This is faster than the rate for the total world population. By the year 2020 the median age in Italy, Switzerland and Germany will be 47 years. Unless the birth rate rises dramatically, these countries, and many other developed countries, face a future in which nearly half of the population will be 50 years old or more.

Active life expectancy is characterised as life without a serious and chronic disability. There is a sharp decline in the active life expectancy between ages 65 and 85 . Females live on average 5 years longer than males and have a corresponding longer period of disability and institutionalised care. In the developed world the elderly are a heterogeneous group. Two thirds of the population over 65 rate their health, as good to excellent, 75 percent have no difficulties with activities of daily living. The majority of the people over the age of 60 years live in urban communities (Barry and Eathorne, 1994). In the developing world the majority of older people live in rural areas, and die before reaching the age of 65 years.

\section{CORRESPONDENCE:}

Dr CJ Eales

Physiotherapy Department University of the Witwatersrand

7 York Road,

Parktown 2193

South Africa

Tel: (011) 488-3450

Email: 159eales@chiron.wits.ac.za 
Education is an important component of health, economic achievement, and the ability to engage actively in all aspects of a modern society. Major differences in the educational status exist between the elderly and younger people. Education is also strongly associated with health. Those with higher levels of education tend to live longer (Kitagawa and Hauser, 1973; Sagan, 1987). The reasons for this connection are many including that a well-informed and educated public is more receptive to public health campaigns and is better able to take more responsibility for maintaining personal health. Retirement is associated with a loss of income and as a result the elderly person becomes economically vulnerable. Income decreases and so does the ability to replace assets. Social benefits thus become more important with advancing age.

The marital status of the elderly is closely related to their living arrangements and economic, social and psychological well being. Marital status also directly influences how care is provided in coping with ill health and functional disability due to chronic disease. Today we find a changing social structure in which more people are living together, they marry later or not at all, and there is a lower rate of childbearing. If these trends persist there will be more older people who are not married who have fewer children to support them. This has the potential to produce an increasing burden on the supportive services (Myers, 1990).

Over the past 30 years most developed countries have witnessed an increase in the numbers of old people living alone. This phenomenon becomes a serious problem when the elderly become frail and can no longer manage on their own. They then need supervised care in a medical care facility or old age home. An increase in the absolute numbers of the aging population in both the developed and developing world is an accepted phenomenon. Patterns of disease and mortality become very important. Health status usually declines quite dramatically in the last year of life and is associated with new diseases and chronic conditions. Morbidity and the health care associated with long term illness is a serious concern in the last years of the twentieth century and will be a major economic issue in the twenty-first century (Brody, 1985).

The common causes of death are frequently divided into four broad categories: heart disease, stroke, cancer and all other causes combined. As one ages these disease processes become chronic and the incidence of coexisting chronic disease increases. One may argue that mortality is beneficial and necessary to society. But the same cannot be said about disability and impaired quality of life which pose serious social and economic costs to the individual and to society.

In most countries in the developing world aging has not yet presented problems. Many of these countries do not consider poverty among the aged a special problem. It is certainly not a problem that is different from the widespread economic deprivation commonly found among the rest of these populations. The economic and social problems of the young usually take priority because populations of these countries are relatively young. Anthropologists have found that as societies develop and become more modern the status of the aged person declines (Tout, 1989). Old age is defined in terms of chronological age when a society becomes modern. Prior to modernisation of a developing country, old age was associated with grandparenthood or succession to eldership. The elderly had a privileged position in the traditional family.

With the increased number of elderly in a population, a situation has evolved in which four or even five generations of a family are still alive. This places a heavy burden on the working adults who may be responsible not only for their children and grandchildren but also for their parents and grandparents. Modern technology has made the skills of the elderly obsolete, and they lack modern education that would enable them to something new. Education has become the yardstick for power and prestige; the status of the elderly is seriously jeopardised because they lack a contemporary education (Apt, 1996). According to Bondevik (1994) "the role of the aged is no longer thought applicable in any society."

Elderly women in the rural areas of developing countries have very little support. It is often more important for women to be economically independent when they are elderly than it was for them during their childbearing age. As the younger members of families move to the cities in search of their fortune the healthy elderly that remain behind will look after the sick and disabled elderly.

The impact of AIDS is described as "the greatest crisis in the recorded history of Africa" AIDS will have a strong impact on grandmothers because they will become responsible for the AIDS orphans. The grandmother will care for their terminally ill children, in the absence of adequate medical and hospice services. She will care for critically ill with limited knowledge of the disease, trying to relieve the suffering. Finally she will arrange for their burial, and at the same time look after the grandchildren who remain in the family.

\section{HEALTH AND DISEASE IN THE ELDERLY}

Health is perceived by the elderly in terms of functional status rather than the presence of disease (Partridge et al, 1996). The factors that influenced most of the elderly peoples' perception of health or disability were whether they could walk and their general levels of activity. Lindgren and co-workers made similar observations in 1994, but they felt that in addition, sleeping problems and general contentment also played an important role in the person's perception of their health. Contentment, according to them was affected by loneliness. Perhaps it would be wise to focus on efforts to improve the elderly's satisfaction of their life situation rather than on marginal improvements of their medical status.

As acute infections come under control other diseases assume greater importance. Acute illness has ceased to be the major medical problem in the developed world and has been replaced by chronic diseases. Limited information is available on the disease patterns of the elderly in the developing world.

According to a survey conducted by the United Nations in 1985 in which 19 countries in the developing world responded the following chronic diseases were mentioned and ranked in order of prevalence: 
- Cardiovascular disease

- Hypertension

- Diabetes

- Diseases of the digestive system

- Cancer

- Rheumatic disease

- Opthamological disease

In both the developed and the developing countries the most important causes of death are heart disease, stroke and cancer. Cardiovascular disorders and stroke will be discussed as examples of chronic diseases that impact on the lives of the elderly.

\section{CARDIOVASCULAR DISORDERS}

Cardiovascular performance deteriorates with age and in both the developing and developed world it is the primary cause of death in the elderly. It is not always clear whether the decline of function is purely a consequence of aging or to what extent it is the result of poor lifestyle and/or disease. Atherosclerosis, can present as an obscure disease but results in severe functional impairments. As a result of the impairment the patient's lifestyle can change drastically and this may result in inactivity which has an effect not only on the function but also the size of the heart (Lakatta, 1992).

The extent of the decline in the maximum work capacity and maximum cardiac output with advancing age varies according to the physical condition of the patient and is also affected if there is underlying pathology. Astrand (1988) observed that it seems easier to motivate elderly people who are already active than their more sedentary counterparts. When activity and training is sustained or even increased it is possible to halt the downward slope in cardiorespiratory function for at least $10-20$ years (Astrand, 1988). The problem however is that when people retire they expect to "slow down" and enjoy a well earned rest" and any attempt to induce them to exercise is met with considerable resistance. This is particularly so when people have engaged in heavy physical labor during their working years.

Physical activity is dependent on the maximal oxygen uptake (Shephard, 1994). Maximal oxygen uptake is dependent on the cardiorespiratory system, body mass and the mechanical efficiency of movement. In the healthy elderly these systems may be compromised. There is stiffening of the rib cage and a resultant increased respiratory workload, which is aggravated if the patient has been a heavy smoker. Older people tend to have an increased body mass and the energy cost of many activities is almost directly related to body mass. This frequently leads to poor performance. The movements of older people are also mechanically less efficient as a result of tissue changes, changes in joint surfaces. Changes in the central nervous system can lead to tremors and poor coordination. The cumulative effects of these changes are quite small in healthy elderly people but quite marked in the presence of disease.

Physical inactivity is a risk factor for many conditions in the elderly such as obesity, osteoporosis and diabetes. Aging is associated with a reduction in physical activity and this results in deconditioning, weakness and fatigue. As the individual experiences a physical decline there is an accompanying loss of a sense of wellness, anxiety and depression. The result is that the elderly patient becomes poorly motivated and this results in a greater reduction in physical activity

Cardiorespiratory fitness in the elderly can be improved through aerobic exercise programs. Participation in exercise programs of modest intensity should result in improved fitness and improved quality of life. Improved quality of life should be the ultimate goal when prescribing an exercise program for an elderly patient.

\section{CEREBROVASCULAR ACCIDENT}

The cerebrovascular accidents (CVA) or stroke, is the second most common cause of death and disability in the elderly. While cardiovascular disease is responsible for an increasing number of deaths and disability in the older age group and accounts for almost 50 per cent of deaths in persons over the age of 65 , stroke is responsible for 20 per cent of all deaths from cardiovascular disease.

In the developed world the majority of stroke patients are over the age of 65 and half of this group is over the age of 75 . As the proportion of older people in the world rises, health professionals will treat and manage an increasing number of older stroke survivors in the future (Brunton and McCullough, 1995). The predisposing factors in CVA in the elderly include hypertension, heart disease and impaired cardiac function, raised blood lipids, diabetes, obesity, race and a family history of stroke. Cigarette smoking, alcohol abuse and physical inactivity are life-style factors that contribute to CVA.

About 50 percent of all CVA survivors have some residual physical disability. Many need care and support at home; some are not able to cope at home with assistance and must move into a supported environment. When institutionalised care is not possible, caregivers experience serious stress in the demanding role of providing care. Many patients who have had a CVA with a mobility disability experience depression associated with it. The quality of life may be severely affected due to problems related to movement around the home and neighbourhood, or getting from home to anywhere else. If public transport is available they may not have access to it, or may not be able to get on it. Pavements are frequently uneven or unsafe, and make walking difficult and dangerous. In the absence of pavements the ground surface is often uneven.

Ideally individuals who are disabled as a result of a CVA should be in contact with day centres and self-support groups. But in developing countries these people may not be seen again after discharge from hospital unless they experience a health crisis. The CVA patients that survive are frequently those who have become functionally independent (Hale, 1998).

We can use South Africa as an example of the developing world where we find more than 3 million black people are hypertensive (Steyn et al, 1992). This number is greater than in any other racial group in South Africa. We can expect that the incidence of stroke is also much greater. In South Africa the circumstances of the aged person with chronic disease in impoverished urban areas is decidedly inferior to that in rural areas due in large part to disintegration of the extended family (Scotch, 1960). In a community-based epidemiological 
survey of the socio-economic circumstances and functional abilities of elderly black persons researchers found that the extent of disabilities among the aged was not as great as expected (Bester et al, 1991). The authors hypothesised that this was probably due to the fact that only those persons who were independent walkers, survived. There is no available information on life style satisfaction or depression in elderly stroke victims in most developing countries. However this information is currently being sought by $\mathrm{L}$ Hale in her research on the survivors of stroke in Soweto, South Africa (Hale, 1998).

\section{PHYSICAL DISABILITIES IN OLDER ADIILTS}

Although diseases are the major contributing factors associated with disability, they are not the only factors (Fried et al, 1994). A small proportion of persons without any disease have difficulty in completing certain tasks related to activities of daily living, mobility, upper extremity function and tasks dependent on cognition. It is important in the care, management and education of the elderly person that the health care professional be cognisant of the following potential problems:

1. Loss of mobility and function

2. The presence of chronic pain

3. Depression

These problems all have a profound effect on the quality of life of the elderly.

\section{Loss of mobility and function}

Deconditioning is described as the multiple changes occuring in organ systems induced by inactivity and restored by activity (Siebens, 1990). Deconditioning results from physiological changes caused by decreased activity or inactivity and leads to functional losses in activities of daily living. The way in which a patient responds to these changes are determined genetically and the also to the lifestyle choices made by the patient. A commitment to health from an early age leads to a much healthier elderly person. By adopting a healthy lifestyle the elderly can contribute to their "wellness".

The most significant organ changes that health care professionals encounter occur in the cardiopulmonary and musculoskeletal systems (Vorhies and Riley,
1993). Mobility is a basic human function essential for individual's independence, to maintain social and intellectual interaction and the basic activities of daily living. Loss of mobility and the occurrence of falls are two of the major causes of a limited quality of life and increased dependence (Baker and Harvey, 1985). Falls are the leading cause of fatal injury in the population over the age of 75 years. Deconditioning, characterised by muscle weakness, impaired gait and balance may contribute in important ways to the experience of falling and puts special importance on the role of physical activity in the management of this problem. Falls frequently produce minor injuries but often can result in hip fractures, head injuries and deaths. Decreased hearing and vision, orthostatic hypotension and cardiovascular disease producing syncope are often related to falls. Falls and immobility may be as a result of impaired sensorimotor functions. Maintaining an upright position during standing and walking requires quick responses to external forces. If a person is unable to make these corrections it may lead to a loss of balance and falls. Muscles of older people contract and relax more slowly than in young adults. This slowing may be as a result of the reduced contribution of Type 11 muscle fibres to the twitch contraction. It may also be due to slower protective reactions which are evident in the elderly.

The gait of the elderly is also affected. The reduction in walking speed is mainly due to the decreased stride length. Normal gait depends on free passive joint mobility, an adequate strength of the involved muscles as well as sufficient levels of fitness.

Walking and balance require power output during leg movement. In the elderly weakness of certain leg muscles have been demonstrated. The strength of the dorsiflexors of the ankle are profoundly diminished (Whipple et al, 1987). Older people can not effectively control posterior sway and it is possible that a backwards loss of balance may be due to weak dorsiflexors. There is a loss of proprioception with age and touch sensitivity also decreases with age. It seems possible that impaired sensory function may contribute to the poor postural response of fallers.

Advancing age brings loss in muscle strength. This deterioration begins at the age of 45 years and progresses from there by $1.5 \%$ per year. Men are consistently stronger than women of the same age and the quadriceps strength of elderly men is greater than that of elderly women. Elderly men have a much greater capacity for weight bearing functional capacities than women of the same age (Young, 1992).

Power is the rate of performing work. The slowing of muscle contractions as the person grows older results in maximal power. This decrease is greater than the decrease in maximal strength so that by the age of 80 years there is a $45 \%$ decrease in power and only a $27 \%$ in strength (Schock and Norris, 1970). The healthy 20 year old female requires 50 $70 \%$ of her maximal quadriceps contraction to rise from a low, armless chair. In order to do the same movement a healthy 80 year old female would have to use a maximal quadriceps contraction. It is then said that the healthy 80 year old woman has reached her "threshold" for this activity. Once a threshold is reached very little decrease in strength or power will make an activity impossible. This has serious functional implications when considering a low armless toilet and it is for this reason that grab rails should be considered in toilets used by the elderly.

The strength of muscles in the elderly can be improved by appropriate training of the specific movements involved. It is not enough to strengthen the relevant muscles but it is necessary to train the specific movements involved (Young, 1992).

\section{Pain in the elderly}

Pain is a common symptom of disease experienced by the elderly. A number of medical conditions produce pain and may severely alter the person's quality of life and affect physical functioning.

According to Herman and Scudds (1995) the most common disorders producing pain in the elderly are:

1. Disorders of the musculo-skeletal system. More than 50 percent of people over the age of 65 experience pain from arthritis. 
2. Rheumatoid disorders such as fibromyalgia and myofascial pain syndromes

3. Osteoporosis associated with the degenerative processes producing neck and back pain

4. Malnutrition

5. Lack of adequate physical conditioning and limited movement

6. Neurogenic pain involving disorders of the peripheral or central nervous system

7. Disorders of vascular origin such as migraine (Herman and Scudds, 1995)

The experience of pain results in physiologic events that have an impact on the pain and the psyche. Release of norepinephrine at the sympathetic nerve endings sensitises nociceptors, enhances pain transmission, and perception of pain. When pain persists, one effect is a mood of depression that results in part from changes in the monoamine metabolism of the brain. In addition, catecholamine levels and serotonin metabolism may change during the aging process, which may result in altered sleep patterns and depression. Both these factors have an effect on the patient's experience of pain. Emotions such as fear, anxiety and efforts to relieve the pain, occupy increasing amounts of time and energy, and contribute to the overall mood of depression. Pain frequently subsides with explanation, treatment and reassurance. Health professionals are in a good position to ameliorate the effects of pain.

Helme and Katz (1993) stress that behavioural strategies should be part of the pain management for patients with chronic disease to discourage inappropriate behaviours and encourage coping strategies. Herman and Scudds (1995) point out that pain is a perceptual event. The experience and the intensity of pain is affected by what the individual thinks, feels and does. Older people differ considerably in the way they respond to pain. Symptoms of chronic pain may resemble the symptoms of depression to such an extent that it is not possible to distinguish between the two. Depression can interfere severely with the outcome of rehabilitation. Depression is present in ten percent of adults over the age of
65 who are free of illness.

The incidence is increased to $30-40$ percent and can be as high as 83 percent in elderly patients suffering from disease or chronic pain. The manner in which people interpret their pain influences the intensity of their pain as well as the outcome of interventions to treat the pain (Herman \& Scudds, 1995).

\section{Depression, physical illness and disability.}

Depression has been defined as the loss of hope and faith (Carlsen 1996a). The majority of old people believe that their lives have turned out better than expected and do not experience depression and are not unhappy or unfulfilled (Murphy et al.1988). It is important to recognise the signs and symptoms of depression as early as possible because it is treatable by various medical or social measures. Depressive symptoms are more common in older people, but depression is not more common with advancing age. These depressive symptoms may be recognised by the appearance of a sad affect and limited responsiveness to stimuli in the environment that presents as low energy most of the day (Reynolds 1995).

A close association seems to exist between physical ill health and symptoms of depression in old age. Reactive depression may be a result of psychological reactions to physical illness and the process of adapting to life style changes required subsequent to disability and handicap. Depressed mood may lead to self-neglect, inadequate nutrition, and self-harm which in turn leads to physical disease. Many physical diseases have a specific association with depression such as the mood disorders that occur after stroke. Many malignancies, cardiovascular disease, metabolic and endocrine disorders, have also been linked to severe depression (Ouslander, 1982). The death rate of patients with depression is consistently higher than that of the general population. While it is true that these patients generally have poor health, the physical health problems alone do not explain this observation (Murphy et al, 1988).

\section{EXERCISES AND AGING}

The most important challenge to the health care professionals is to address the decreasing functional capacity of the elderly. A well-designed program is one of low to moderate intensity and this may be the most cost-effective way to address the problem of inactivity. For the greatest majority of elderly people living in the developed world, the most effective and safe exercise is a simple walk program (Barry and Eathorne, 1994). Elderly people in the developing world as a rule do not have easy access to transport and have had to rely on their ability to walk in order to cope with their tasks of daily living. For these elderly people exercise programs (especially a walking program) is of little value but programs of management and education are vital.

One of the most obvious benefits of exercise is an immediate elevation of mood (Sime, 1990). This elevation of mood in turn has a favourable influence on the patient's perception of his/her health status. An exercise progamme, by elevating the mood and improving the elderly person's perception of his/her health status, will assist the older person to live with minor aches and pains. This will result in a decreased demand for medical services and increased levels of functional capacity and independence.

In conclusion it can be said that physical activity increases elderly people's physical ability and as a result their physical functioning. As physical function improves the quality and possibly even the quantity of life for the elderly person is improved (Caspersen et al, 1994).

\section{CONCIUSION:}

The health professional must always bear in mind that many older people do not feel different just because they are advanced in years. Their identities are not negatively influenced by the fact that they are elderly, and they do not feel old or different or disconnected from their younger selves. They have a well developed sense of who they are. On the other hand they are so markedly different from one another that we can not generalize about them. The fact is that the longer we live the more different form each other we become because our life experiences are different. So two young children could be compared more easily to one another than two eighty year olds. 
Neugarten refers to the older person as a translator and interpreter of experience, a person who creates a future and recreates a past (Neugarten, 1972). Those who are successful and survive into old age are individuals made stronger by a wide variety of conditions that life has presented. We can admire them for their courage to grow old and in doing so acquiring the real wisdom that only age can teach.

\section{REFERENCES}

Apt N A 1996 The Ghanaian tradition: Kin, clan and informal caring systems. In: Apt N A Coping with Old Age in a Changing Africa. Aldershot: Avebury: 16 - 33

Astrand P O 1988 Exercise physiology in the mature athlete. In Sutton J, Brock R M (editors) Sports medicine for the mature athlete. Indianapolis: Benchmark

Baker S P, Harvey A H 1985 Fall injuries in the elderly. Clinics in Geriatric Medicine 1: $501-512$

Baltes P, Baltes M M 1991 Successful ageing, pp. 397. Cambridge: Cambridge University Press.

Barry H C, Eathorne S W 1994 Exercise and ageing: issues for the practitioner sports medicine. Medical Clinics of North America $78: 357-376$.

Bester F C J, Weich D J V, Albertyn E W 1991 Socio-economic circumstances and functional abilities of elderly black persons in the Orange Free State. South African Medical Journal 82: $110-113$

Bondevik M 1994 Historical, cross-cultural, biological and psychosocial perspectives of ageing and the aged person. Scandinavian Journal of Caring Science 8: $67-74$.

Brody J 1985 Prospect for an ageing population. Nature 315: $463-466$

Brunton K, McCullough C 1995 Stroke. In: Pickles B, Compton A, Cott C (editors) Physiotherapy with Older People. London: W B Saunders: $230-254$
Carlsen M B 1996a Creative Ageing: A Meaning Making Perspective. New York: W W Norton \& Company Ltd: $11-28$

Carlsen M B 1996 Creative Ageing: A Meaning-Making Perspective. New York. W W Norton \& Company Ltd: 26

Caspersen C J, Kriska A M, Dearwater S R 1994 Physical activity epidemiology as applied to elderly populations. In: Bailliere's Clinical Rheumatology 8(1): 7 - 27

Fried L P, Ettinger W H, Lind B 1994 Physical disability in older adults: A physiological approach. Journal of Clinical Epidemiology 47: $747-760$.

Fries J F 1980 Ageing, natural death, and the compression of morbidity. The New England Journal of Medicine 303: 130 - 135.

Gonzalez-Aragon J In: Tout K 1989 Ageing in Developing Countries. New York Oxford University Press.

Hale L A, Eales C J 1998 Recovery of walking function in stroke patients after minimal rehabilitation. Physiotherapy Research International 3: 194205

Helme R D, Katz B 1993 Management of chronic pain. The Medical Journal of Australia 158: 478 - 481

Herman E, Scudds R 1995 Pain. In: Pickles B, Compton A, Cott C (editors) Physiotherapy with Older People. London: W B Saunders: 289-304

Kitagawa E M, Hauser P M 1973 Differential mortality in the United States. Cambridge. Harvard Press.

Lakatta E G, Gerstenblith G 1992 In: Evans J G, Williams T F (editors) Oxford Textbook of Geriatric Medicine. Cardiovascular Disorders. New York. Oxford University Press: 271 - 284

Lindgren A, Svardsudd K, Tibblin G 1994 Factors related to perceived health among elderly people: The albertina project age and ageing 23: $328-333$

Murphy E, Smith R, Lindesay J 1988 Increased mortality rates in late life depression. British Journal of Psychiatry 152: 347 - 353

Ouslander J G 1982 Physical illness and depression in the elderly. Journal of the American Geriatrics Society 30: 593 - 599

Myers G 1990 Demography of ageing. In: Binstock R H, George L K (editors) Handbook of ageing and the social sciences. New York. Academic press.

Partridge C, Johnston M, Morris L 1996 Disability and health: perceptions of a sample of elderly people. Physiotherapy Research International 1:17-29.

Rabbit P 1992 Ageing Gracefully. The Lancet 339: $1157-1158$.

Reynolds C F 1995 Recognition and differentiation of elderly depression in the clinical setting. Geriatrics 50: S-6-S-15

Sagan L A 1987 The Health of Nations. New York. Basic Books.

Scotch N A 1960 A preliminary report on the relation of socio-cultural factors to hypertension among the Zulu. Annals of New York Academic Science 84: 1000 - 9

Shepard R J 1993 Exercise and ageing: Extending independence in older adults. Geriatrics, 48: 61 - 64

Siebens H 1990 Deconditioning. In: Kemp B, Brummel-Smith K (editors): Geriatric Rehabilitation, Boston: Little Brown: 177

Sime W E 1990 Discussion: Exercise, fitness and mental health. In: Bouchard C, Shehard R J, Stephens T, Sutton J, McPherson B (editors). Exercise, Fitness and Health. Champaign, I L: Human Kinetics: $627-633$

Steyn K, Fourie J, Bradshaw D 1992 The impact of chronic diseases of life style and their major risk factors on mortality in South Africa. South African Medical Journal 82: 227-231

Tout K 1989 Ageing in developing countries. New York. Oxford University Press for Help Age International.

Vorhies D, Riley B E 1993 Deconditioning. Clinics in Geriatric Medicine 9: 745 - 763.

Whipple R, Wolfson L I Amerman P 1987 The relationship of knee and ankle weakness to falls in nursing home residents: An isokinetic study. Journal of the American Geriatrics Society $35: 13-20$

Willing J Z 1981 The reality of retirement: The inner experience of becoming a retired person. New York. William Morrow.

Young A 1992 Strength and power. In: Evans G J \& Williams T F (editors) Oxford Textbook of Geriatric Medicine. New York: Oxford University Press: 597 - 601

\title{
DYNAMIC PHYSIOTHERAPISTS REQUIRED TO STAFF THE NEW WITS ACADEMIC PHYSIOTHERAPY PRACTICE.
}

\author{
FOR MORE INFORMATION OR \\ TO ARRANGE AN INTERVIEW, PLEASE CONTACT MICHELE ON: \\ (011) 795-1297 OR 0824161370
}

